九州大学学術情報リポジトリ

Kyushu University Institutional Repository

\title{
Numerical Modelling of a Composite Sandwich Structure Having Non Metallic Honeycomb Core
}

Kumar, Anil

MAE Department, G B Pant Engineering College

Arindam Kumar Chanda

MAE Department, G B Pant Engineering College

Angra, Surjit

ME Department, NIT, Kurukshetra

https://doi.org/10.5109/4742119

出版情報：Evergreen. 8 (4)，pp.759-767，2021-12. 九州大学グリーンテクノロジー研究教育センター バージョン：

権利関係 : 


\title{
Numerical Modelling of a Composite Sandwich Structure Having Non Metallic Honeycomb Core
}

\author{
Anil Kumar ${ }^{1, *}$, Arindam Kumar Chanda ${ }^{1}$, Surjit Angra ${ }^{2}$ \\ ${ }^{1}$ MAE Department, G B Pant Engineering College, New Delhi, 110020, India \\ ${ }^{2}$ ME Department, NIT, Kurukshetra, 136119, India \\ *Author to whom correspondence should be addressed: \\ *E-mail: anilapmae@gmail.com
}

(Received June 4, 2021; Revised September 10, 2021; accepted November 11, 2021).

\begin{abstract}
The composite sandwich structures are in great demand in aircraft, automotive and sports industries because these materials possess light weight, high flexural strength and stiffness. In present research paper, initially a composite sandwich structure, having Carbon Fibre Reinforced Plastic (CFRP) face sheets and a regular hexagon Kevlar ${ }^{\circledR}$ Honeycomb core material, in the form of an equivalent solid, has been modelled. 'Gibson and Ashbey' model for regular hexagon double wall thickness honeycomb core has been employed to determine the equivalent orthotropic properties of Kevlar ${ }^{\circledR}$ Honeycomb core. "Three point bend test (3PBT)" has been performed on sandwich panel using Ansys as per ASTM C393-00 standard and ultimate load and deformation have been calculated. Then for experimental result, a composite sandwich has been fabricated and a 3PBT also has been performed on it. The analytical value for deflection has also been found using the ASTM C 399-00 standard. The value of stiffness obtained from finite element model is successfully compared with the experimental and analytical solutions and the numerical model predict to an excellent stage of the static behaviour of the material whilst compared with the experiments.
\end{abstract}

Keywords: Composite sandwich; Kevlar®; Honeycomb; Orthotropic; Numerical Modelling; 3PBT

\section{Introduction}

To obtain continuous increase in performance, designers are constantly looking for lighter, stronger and more durable materials. Different types of materials have been developed such as alloys and composites to fulfill the demand of the different types of industries. Composites are getting an edge in this competition because they possess most of the required properties. Different types of composite materials having different structures have been developed in the recent years. Now a days the composite sandwich structures are most widely used materials in facilities such as aircrafts, railways, automobiles and sports because these materials have numerous desirable properties like low weight, high flexural strength, stiffness, fire and corrosion resistance.

A composite sandwich structure is similar to that of an I-beam as shown in Figure 1. It consists of 3 main elements explained below-

a. The face Sheets -These are higher in weight and density but low in thickness and are responsible for bearing the bending stresses acting on the sandwich structure. Carbon, Glass and Basalt Fibers are most widely used as Facesheet materials for fabrication of composite sandwich structures.

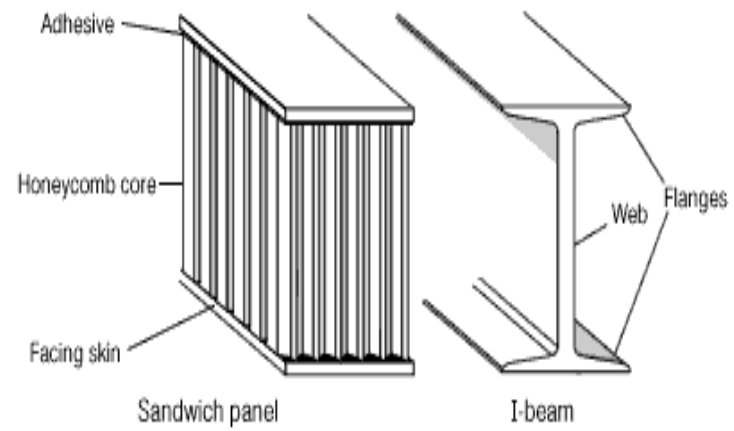

Figure 1- I beam and a Sandwich composite

b. The core -It is the low density materials and lighter part of the composite sandwich structure with higher thickness as compared to facesheets. Mainly four types of cores are used in sandwich structures i.e. Corrugated, Honeycomb, Balsa wood and Foams. Core is responsible to bear the shear stresses acting on the sandwich panel. For this reason, always such a core has been chosen which would not fail under the applied transverse load and whose shear modulus is high enough to give the required shear stiffness. Honeycomb core can be made of metallic or non metallic materials such as aluminium, impregnated glass or Aramid fibre mats, such as Nomex. 
c. The adhesive- The purpose of an adhesive in a composite sandwich structure is to provide a good bond between the materials components. Epoxy Resins are most widely used adhesive as they are low temperature curing materials, normally between 20 to $90{ }^{\circ} \mathrm{C}$. The biggest advantage of use of epoxy is that due to the absence of solvents, epoxies can be used with almost every type of core material. Epoxies are available in almost every form such as paste, films, powder, or as solid adhesives. The shear strength of most of the epoxies are about 20-25 MPa. Also other adhesives are available such as Modified Epoxies, Phenolics and Polyurethanes and Polyester and Vinyl ester Resin etc.

The performance and different mechanical properties of a composite sandwich panel depends on the different design factors (such as material, thickness, orientation of factsheet and core, core cell size, use of adhesive, panel shape etc.), and manufacturing methods. Double-wall thickness regular hexagon honeycomb type cores are the extensively used cores because of its low density and relatively higher out-of-plane compression and shear properties. Any defects amassed during production or in service of the sandwich panel will impact the properties and overall performance of the entire composite sandwich structure. The failure of sandwich structures may be due to core shear failure, skin failure, nearby wrinkling, delimitation between the core and face sheet. The core failure may be due to either shear or compressive stresses when the load is applied to the sandwich panel.

The finite element technique (FEM) is the widely used and accepted simulation method to predict the physical behavior of systems and structures. Many of the times the analytical solutions are not suitable for most of regular engineering problems, so the numerical techniques like FEM had been developed to discover an answer for the governing equations of the individual problem. A lots of research work has been done in the field of numerical modelling during the last 4 decades which enables engineers today to perform simulations close to reality. Nonlinear phenomena in structural mechanics such as nonlinear material behavior, larger deformations or contact issues and problems having very higher degree of freedom have turn out to be the regular modeling tasks. In a mathematical sense, the finite element method answers an approximate numerical solution of the considered problem. If experimental or analytical results are available it is easily possible to verify any finite element result, otherwise the accuracy of the results obtained from the numerical analysis cannot be assured. To predict the mechanical behavior of any material accurately, Finite Element Analysis is a reliable tool way without experiments but with the limitation that the user should have fundamental software knowledge along with ability to select the appropriate elements and algorithms ${ }^{1)}$.
For finite element analysis of a composite sandwich in the Ansys Software, the face sheet and regular hexagon honeycomb core has to be modelled and assembled. For modelling of the face sheet and core the different in and out plane properties of these elements are needed. The thickness of the facesheet materials is very low and most of the face sheet material's (carbon, glass etc.) elastic properties are easily available in the Ansys as in build materials properties. But the Honeycomb core possesses greater height in a composite sandwich structure and it also exhibits the orthogonal properties. So to develop an equivalent solid of such a core, all the 9 in and out plane properties of the core have to be calculated. The stiffness of the sandwich structures increase with core thickness. The core material compressive strength and modulus increases with the increased core thickness as the sandwich structure also increases ${ }^{2)}$. The numerically determined orthotropic properties using Strain energy-based homogenization technique can be successfully used for generating an equivalent solid of a honeycomb core which ultimately can be used for performing 3PBT on sandwich panel to determine the deformation and stiffness of a sandwich panel. For producing representative volume element (RVE) of a core, only a single cell can be selected and homogenization technique instead of selecting a entire core cells can be utilized which will result in considerably reduced computational time and effort ${ }^{3,7,11)}$. Gibson and Ashbay initially determine the formulae for detection of nine orthotropic properties for honeycomb materials with constant wall thickness followed by the number of revisions by 'Zhang and Ashbey' and 'Klintworth and Stronge' to include the double wall thickness for the out of plane values using homogenization techniques. It has been observed that the modified 'Gibson and Ashbey model' and Chamis's Model are the best analytical models to determine the orthotropic properties of a honeycomb core ${ }^{4)}$. After FEA of sandwich structures, for determining the orthotropic properties of the core, it has been observed that the only two out-of-plane properties i.e. shear modulii $\left(\mathrm{G}_{\mathrm{xz}}\right.$ and $\mathrm{G}_{\mathrm{yz}}$ ) are the most influential core material properties ${ }^{5,6)}$.

Three point bending test (ЗРBT) can be performed using numerical analysis and its result can be verified using the experimental setup and for the investigation of various mechanical properties of composite sandwich beams. The FEA is the good option for testing of different sandwich structures ${ }^{8,9,22)}$. The Analytical expressions have also been developed for determining the effective elastic properties of cellular hexagonal honeycomb using the elemental beam theory. Most of the analytical expressions obtained for determining the orthotropic properties of honeycomb core almost confirm the Gibson and Ashbey model ${ }^{10)}$. Researchers have successfully evaluated and described the methodology for finding the in-plane and out-of-plane effective elastic constants of the existing continuum models of the 
honeycomb cores using different models. "Gibson and Ashbey model" is one of the best useful model for this type of analysis and evaluation ${ }^{12)}$. Experimental, numerical and analytical analyses of composite sandwich structures have been done to determine the effects of varying honeycomb core ribbon orientation and varying face sheet thickness's have on the flexural behavior of honeycomb sandwich and it has been observed that the stresses are different in two directions of a honeycomb core i.e. the weakest angle is $62^{\circ}$ and the L-direction is the strongest direction ${ }^{13)}$. Due to the different manufacturing methods, the different honeycombs have different in and out-of-plane properties. But, Nomex honeycomb core is weak in, out-of-plane direction. The unit cell models with shell elements can be effectively used to solve Nomex honeycomb cores crushing problems and with solid elements and cohesive elements it can also be used to determine the debonding fracture and the influence of bonding quality on the mechanical behaviour of the double thickness cell wall honeycomb core $^{14)}$. Using the different software as per requirement, if modelling will be been done properly, the results can be satisfactory ${ }^{15)}$.

It has also been found that the different properties of sandwich composites are also affected by type of core material $^{16)}$. The percentage of fiber used in the fabrication of sandwich plates greatly affects the mechanical properties of the composites ${ }^{17)}$. By using hexagonal core, the composite material weight saving is $39 \%$ as compared with other composite material ${ }^{18)}$. The composite fabricated using Kevlar ${ }^{\circledR}$ Honeycomb core and carbon fiber facesheet reported excellent stiffness performance ${ }^{19)}$. Apart from activated carbon, the Bagasse waste has potency for adsorbent powder and it can be used as a core material, where such type of property is desired $^{20)}$. For proper experimental testing the samples must be of accurate dimensions and for having proper panel shape. Composites panel can be properly cut for testing using the EDM machine ${ }^{21)}$.

From the literature review, it has been observed that the most of the research has been done of Aluminium, Steel, Polyurethane foam and Glass core. A number of research papers are also available on Nomex Honeycomb core but not much data and research work is available on different 'In and Out plane properties' of Kevlar ${ }^{\circledR}$ Honeycomb core. So, double thickness cell wall regular hexagonal Kevlar honeycomb can be chosen as a core material. 'Gibson and Ashbey' Model can be used to determine the effective elastic properties of the Honeycomb core. Only two out-of-plane properties i.e. shear modulii $\left(G_{x z}\right.$ and $\left.G_{y z}\right)$ are the most influential core material properties determining the stiffness of sandwich panel. 3PBT can be performed using Finite Element analysis and can be verified using the experimental setup.

The objective of this study is to develop a Numerical model of a composite sandwich structure, having having
Carbon Fibre Reinforced Plastic (CFRP) face sheets and a double thickness cell wall regular hexagonal Kevlar honeycomb core material, in the form of an equivalent solid.

For numerical modelling of a sandwich structure, a sandwich structure, having Carbon fiber reinforced face sheet and a non metallic material (Kevlar® Honeycomb) will be modelled. Gibson and Ashbey model formulae for honeycomb core will be employed to determine the equivalent orthotropic properties of Kevlar ${ }^{\circledR}$ Honeycomb core so that the honeycomb core can be converted into an equivalent solid. 3PBT will be performed on sandwich panel using Ansys as per C393 ASTM standard and ultimate load, deformation and the equivalent stiffness will be calculated. Then for experimental results, a composite sandwich will be fabricated and a 3PBT also will also be performed on it. The value for deflection will also be found analytically using the ASTM C399-00. The stiffness value obtained from finite element model will then be compared with the experimental solution analytical method. If the values from different analyses will be successfully match then the model will be assumed as valid and will be recommended for numerical modelling of other similar sandwich panels having different core materials.

\section{Materials and Methods}

\subsection{Materials used}

The CFRP, Kevlar Honeycomb and Epoxy have been used as the Facesheet, Core and Adhesive material respectively for design and fabrication of the sandwich structure. The different characteristics of these materials are as under-

a. Face Sheet Material (Carbon fiber) - Carbon fibers have elastic constants almost equivalent to steel, so they act as best material for facesheet. They are resistant to moisture and chemicals and low in weight resulting in, reduced overall weight of the panel. The different properties of CFRP are shown below in Table 1.

Table 1- Properties of Epoxy Carbon Woven

\begin{tabular}{|l|l|}
\hline PROPERTY & \multicolumn{1}{|c|}{ VALUE } \\
\hline Young's Modulus (X- Direction) & $61340 \mathrm{MPa}$ \\
\hline Young's Modulus (Y- Direction) & $61340 \mathrm{MPa}$ \\
\hline Young's Modulus (Z- Direction) & $6900 \mathrm{MPa}$ \\
\hline Poission's Ratio XY & .04 \\
\hline Poission's Ratio YZ & .3 \\
\hline Poission's Ratio XZ & .3 \\
\hline Shear Modulus XY & $195000 \mathrm{MPa}$ \\
\hline Shear Modulus YZ & $2700 \mathrm{MPa}$ \\
\hline Shear Modulus XZ & $2700 \mathrm{MPa}$ \\
\hline
\end{tabular}

b. Material for Core (Kevlar $\left.{ }^{\circledR}\right)$ - Kevlar ${ }^{\circledR}$ has been chosen as core material as it has numerous properties such as Light weight, High Shear modulus, High Thermal and Corrosion Resistance, High stiffness and 
Flexibility in core cell size. The Geometry of a commercial honeycomb cell with double cell wall thickness has shown below in Figure 2.
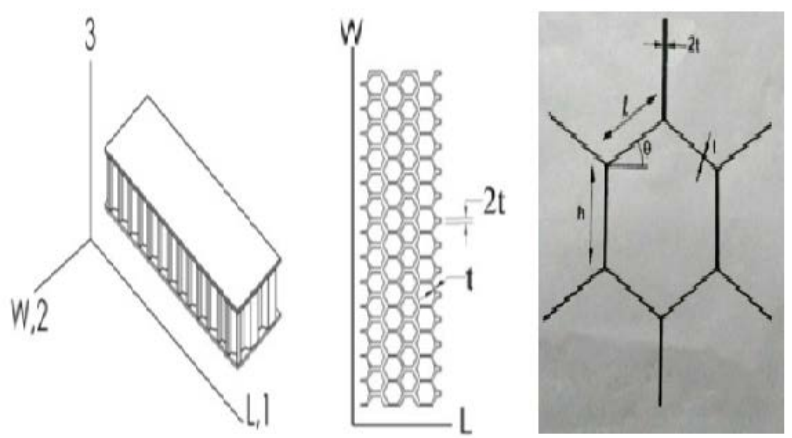

Figure 2- Geometry of commercial honeycomb cell ${ }^{24)}$

The core will bear the shear load which will be acting on the sandwich panel. Kevlar is about five times lighter than steel in terms of the same tensile strength.

As Kevlar ${ }^{\circledR}$ ) honeycomb core is a newer material and its orthotropic properties are not available in the Engineering Data Sources of ANSYS software, it is necessary to find the 9 elastic constants of Kevlar ${ }^{\circledR}$ honeycomb core in order to add and create the equivalent solid structure of core in the Engineering Data Sources of ANSYS software. 'Gibson and Ashbey' analytical formulae have been adopted for calculating the 9 elastic constants of Kevlar® honeycomb core as this model has already been proved as the best suitable model by most of the researchers to determine the equivalent orthotropic properties of Kevlar ${ }^{\circledR}$ Honeycomb core. Plascore PK2 Kevlar honeycomb core has been used for this research and the different In and Out Plane i.e. orthotropic, properties of the core are shown in Table 2.

Table 2- Mechanical and Orthotropic Properties of Kevlar ${ }^{\circledR}$ Core

\begin{tabular}{|c|l|c|}
\hline S.N. & \multicolumn{1}{|c|}{ Property } & Core Height $(12.7 \mathrm{~mm})$ \\
\hline 1 & Cell Size $(\mathrm{mm})$ & 4.8 \\
\hline 2 & Comp. Strength (MPa) & 2.21 \\
\hline 3 & Shear Moduli 'L' $(\mathrm{MPa})$ & 100 \\
\hline 4 & $\rho^{*}{ }_{\mathrm{c}}(\mathrm{kg} / \mathrm{m} 3)$ & 48 \\
\hline 5 & $\rho^{*}{ }_{\mathrm{s}}(\mathrm{kg} / \mathrm{m} 3)$ & 2000 \\
\hline 6 & $\mathrm{G}_{\mathrm{s}}(\mathrm{MPa})$ & 7000 \\
\hline 7 & $\mathrm{E}_{\mathrm{s}}(\mathrm{MPa})$ & 18200 \\
\hline 8 & $\mathrm{E}^{*}{ }_{\mathrm{x}}(\mathrm{MPa})$ & 0.142 \\
\hline 9 & $\mathrm{E}^{*}{ }_{\mathrm{y}}(\mathrm{MPa})$ & 0.142 \\
\hline 10 & $\mathrm{~V}^{*}{ }_{\mathrm{xy}}$ & 0.999 \\
\hline 11 & $\mathrm{G}^{*}{ }_{\mathrm{xy}}(\mathrm{MPa})$ & 0.006 \\
\hline 12 & $\mathrm{E}^{*} \mathrm{z}(\mathrm{MPa})$ & 420.42 \\
\hline 13 & $\mathrm{~V}^{*}{ }_{\mathrm{xz}} \& \mathrm{~V}{ }^{*} \mathrm{yz}$ & 0 \\
\hline 14 & $\mathrm{G}^{*} \mathrm{xz}(\mathrm{MPa})$ & 60 \\
\hline 15 & $\mathrm{G}^{*} \mathrm{yz}(\mathrm{MPa})$ & 100 \\
\hline
\end{tabular}

c. Material for adhesive (Epoxy) - Epoxy Resins are low temperature curing materials, available in almost every form such as paste, films, powder or as solid adhesives and mostly have the shear strength of about 20-25 MPa. Epoxy with hardener has been be used as matrix material.

\subsection{Modelling}

To perform the accurate simulation on the sandwich panel an accurate model is must. For modeling purpose design modular \& ACP has been used. Modelling has been done in the Ansys. The Face sheets have been modelled orthotopically in the Ansys composite prep-post while the homogenised core is modelled in Design modeller available in Ansys.

The Figure 3 shows model of a composite sandwich panel which is having a commercial regular honeycomb core having thin face sheet attached on both of its side.

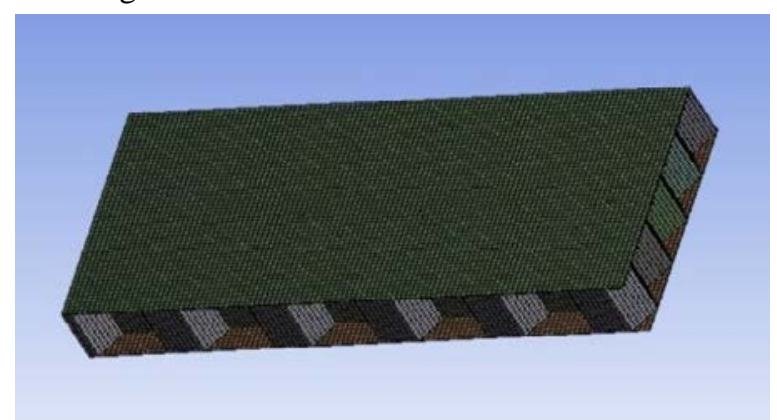

Figure 3- Model of a composite sandwich panel with actual honeycomb core geometry

The model shown above needed too much complex calculations and more time for numerical analysis so the homogenised core is modelled as shown in Figure 4 by replacing honeycomb core cells with a solid core that acts as a honeycomb itself in a macroscopic view. The solid core is given the same orthotropic properties as the honeycomb core. The main advantage of this method is that the number of elements in solid core is highly reduced than the actual honeycomb geometry. Hence this method is computationally cheap.

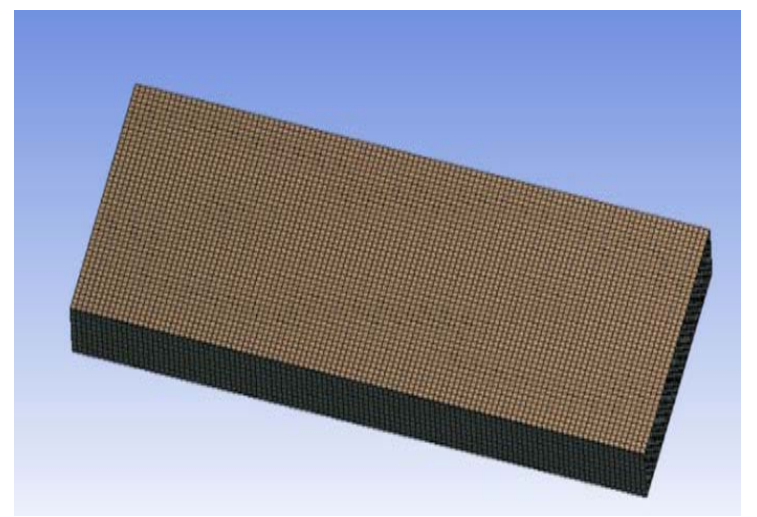

Figure 4- Equivalent Model of Sandwich Panel

\subsection{Meshing}

The equivalent honeycomb core was meshed using solid 186 mesh elements. Shell 181 mesh elements were 
used for meshing the face sheets.

The contact between the face sheet and the core has been considered as bonded so that both acts as an integrated unit. Bonded contact has been assigned such that face sheets have 'contact body' and core has 'target body' setting. Default 'program controlled' has been used to set up the formulation of contact, hence it has been considered the FEA approach as penalty method. The Table 3 shown below shows the Mesh Statistics.

\begin{tabular}{|c|c|c|c|c|c|}
\hline & 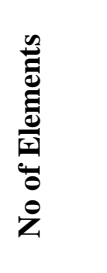 & 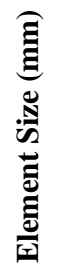 & $\frac{\mathscr{e}}{\tilde{Z}}$ & 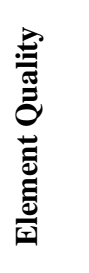 & 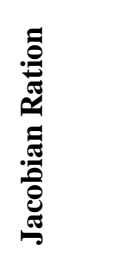 \\
\hline 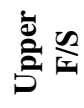 & 4662 & 1.8 & 4816 & $\begin{array}{c}.978- \\
.999\end{array}$ & $1-1.031$ \\
\hline نٌ & 37632 & 1.8 & 168661 & .991 & 1 \\
\hline 离 & 4662 & 1.8 & 4816 & $\begin{array}{c}.981- \\
.999\end{array}$ & $1-1.034$ \\
\hline
\end{tabular}

\subsection{Simulation Procedure and Boundary Conditions}

All three modeled components i.e. facesheet, core and adhesive have been imported in static structure module as shown in the Figure 5.

The 3 rollers are used in all one above and two below the sandwich panel and Zero degree of freedom has been adopted for these two rollers at the bottoms. To simulate the rollers, five degrees of freedom of the center line is fixed except the rotation about y-axis. Load is applied at rate of $16.5 \mathrm{~N} / \mathrm{s}$ until the failure of the sandwich panel.

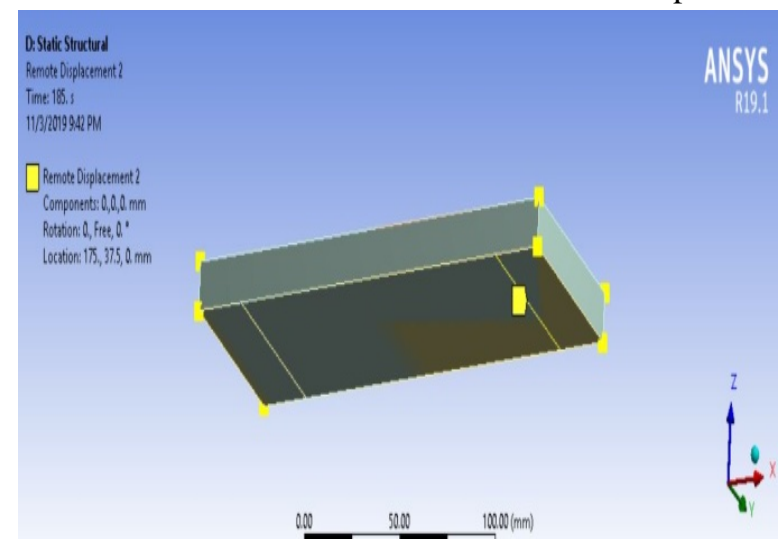

Figure 5- Finally Assembled model

\section{Finite Element Analysis}

For FEA, the following physical properties of sandwich structure have been utilized.

- $\quad$ Facesheet thickness-.8 mm

- $\quad$ Core cell size- $4.8 \mathrm{~mm}$

- $\quad$ Core height- $12.7 \mathrm{~mm}$

- $\quad$ Total Height- $14.3 \mathrm{~mm}$

- $\quad$ Panel length- $200 \mathrm{~mm}$

- $\quad$ Panel width - $45 \mathrm{~mm}$

- $\quad$ Span Length- 150 mm

FEA has been done for finding the Ultimate Load and Deformation at that load. The two Figures i.e. 6 and 7 as shown below give a look of the calculation of force and deformation using FEA.

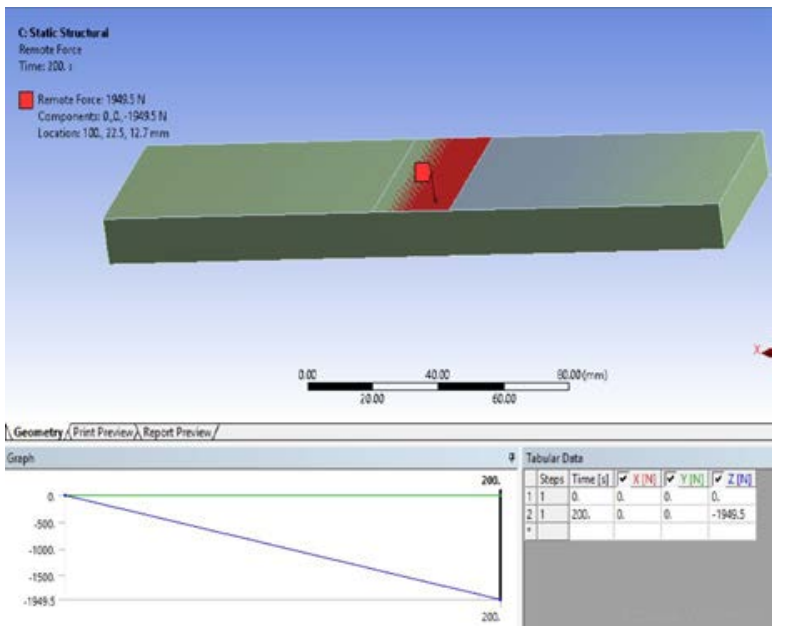

Figure 6- Ultimate Load Analysis using ANSYS

The Figure 6 shown above shows that the Ultimate Load achieved during the three point bending test is 1949.5N.

Figure 7 shown above, nicely shows that the deflection is $2.017 \mathrm{~mm}$ at the ultimate load.

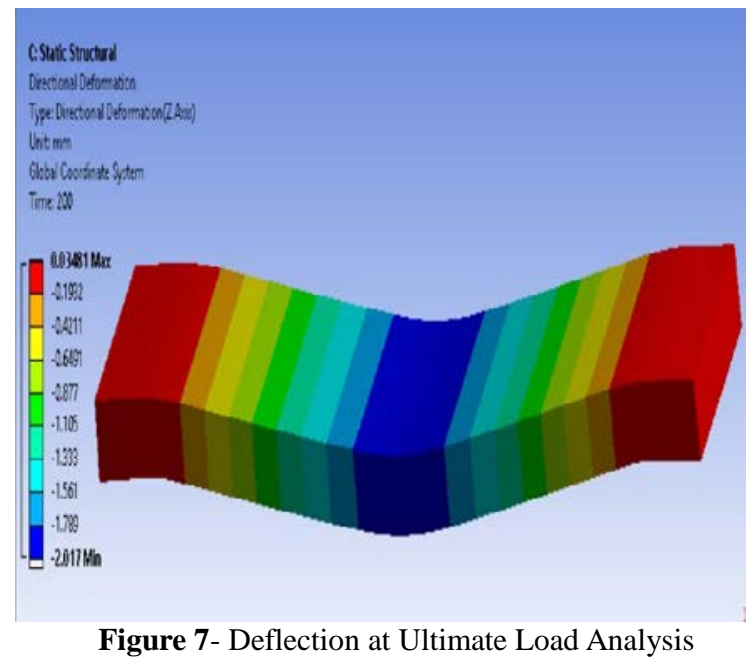

The sandwich panel equivalent stiffness can be calculated as the ratio of load to deflection and it has been found as $966.53 \mathrm{~N} / \mathrm{mm}$. 


\section{Experimental Analysis}

4.1 Fabrication of Sandwich Composite- The apparatus and steps used for the fabrication of Sandwich panel has been described below.

\section{Apparatus and materials required}

$\begin{array}{ll}\text { 1. } & \text { A pair of scissors } \\ \text { 2. } & \text { A metal cutter } \\ \text { 3. } & \text { Roller } \\ \text { 4. } & \text { Gloves } \\ \text { 5. } & \text { Peel plies } \\ \text { 6. } & \text { Sealant tape } \\ \text { 7. } & \text { Masking tape } \\ \text { 8. } & \text { Infusion mesh } \\ \text { 9. } & \text { Vacuum pump } \\ \text { 10. } & \text { Hose and connector }\end{array}$

\section{Steps Used in fabrication of Sandwich Panel}

The entire procedure involves the cutting of fibre sheets in required dimensions and then using these sheets for fabrication. Fabrication involves saturating the reinforcement and then allowing the matrix to form a rigid structure via a chemical reaction. "Vacuum Assisted Hand Lay-up Method” has been utilized for proper spreading and bonding of the resin with the different components.

Step 1: Cutting of Fibre Sheets

Step2: Preparation of Epoxy Resin- Hardener Mixture-Epoxy resin $(300 \mathrm{ml})$ has been taken into a container. Hardener has been added to this resin equal to $18 \%$ of quantity of resin (i.e. $0.18 * 300=54 \mathrm{ml}$ ). This mixture has been continuously mixed for thorough lamination.

Step 3: Preparation of Mould/Work Surface.

Step 4: Layer Reinforcement onto the SurfaceAfter spreading the carbon fiber on the epoxy layer, resin mixture has been applied on the fibre. After that Core has been set on the carbon fabric and epoxy has been applied on it. Then this combination has been bonded on the layer on carbon fiber as shown in Figure 8 below.

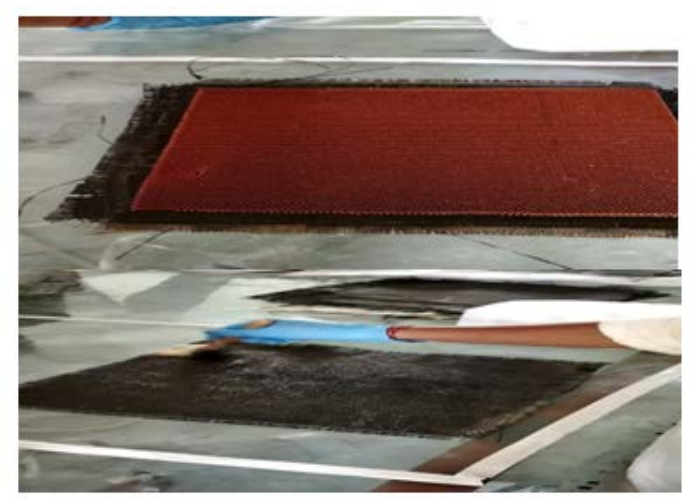

Figure 8- Reinforcing the core with Epoxy Resin

\section{Step 5: Tape the Reinforcement.}

Step 6: Cutting and positioning of the Peel Ply over the Reinforcement

Step 7: Cutting has been cut about the area under the sealant tape and it has been taped with the masking tape over the sealant area.

Step 8: Cutting the bagging film oversize of the sealant area and then film has been sealed with a layer of sealant tape.

Step 9: Then the pump has been connected to the mains supply.

Step 10: Then the Pump has been removed and the Bagging film and all infusion mesh is removed.

Step 11: The reinforcement has been then allowed to cure for 24 hours depending on the ambient temperature.

Step 12: And finally the edges have been trimmed and final composite panel has been achieved.

\subsection{Preparation of sample for 3PBT as per ASTM C393}

3-Point bending tests as per the ASTM standard C393 has been carried out on the composite sandwich panel. The panel shape of composite sandwich specimen has been taken as $200 \times 45 \mathrm{~mm}^{2}$ and the test set up on Universal Testing machine has been shown in Figure 9 below.

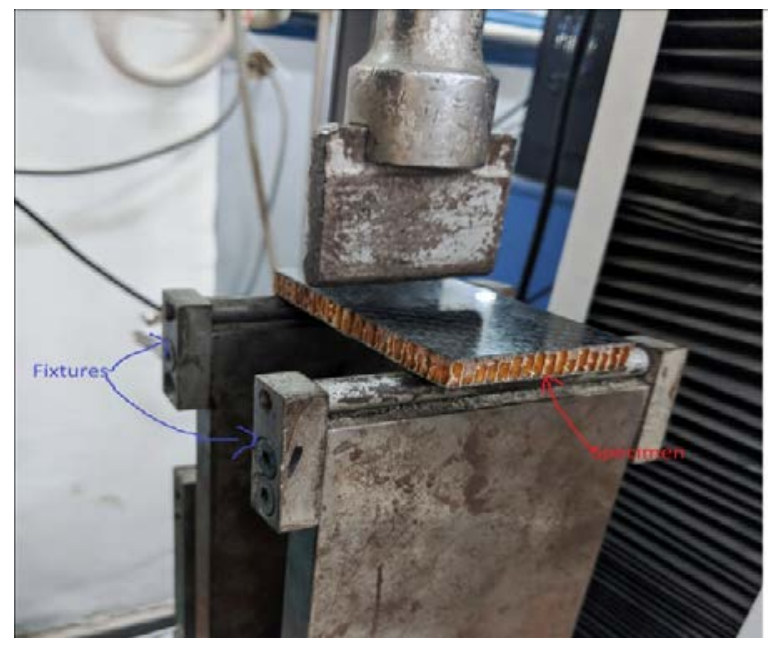

Figure 9- Test setup for three point bending test

The Figure 10 shows a test specimen after the three point bend test. The failure of specimen took place due to Shear crimping as the core is the weaker in shear.

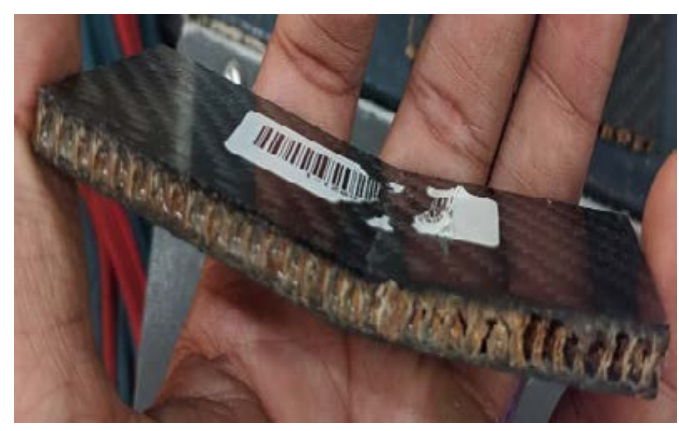

Figure 10- Specimen after three point bending test

The Ultimate load and deflection after 3PBT for composite samples has been shown below in table 4 . 
Table 4- Load and deflection for Sandwich Panel

\begin{tabular}{|c|c|}
\hline Load (N) & Deflection (mm) \\
\hline 00 & 00 \\
\hline 1500 & .76 \\
\hline 1930.8 & 1.82 \\
\hline 788 & 10 \\
\hline 620 & 17 \\
\hline
\end{tabular}

The Table 4 shown above clears that the Critical load for panel is $1930.8 \mathrm{~N}$ and the corresponding deformation at this load is $1.82 \mathrm{~mm}$.

By using the above two values, stiffness has been obtained as $1060.88 \mathrm{~N} / \mathrm{mm}$.

\section{Analytical Analysis as per ASTM Standard C 399-00}

The different dimensions of the composite sandwich structure have been shown in the equivalent sandwich structure in Figure 11. The honeycomb core has been converted into an equivalent solid which has ' $c$ ' as the height.

The facesheets are at the top and bottom of the solid core and each has a thickness of ' $\mathrm{t}$ '.

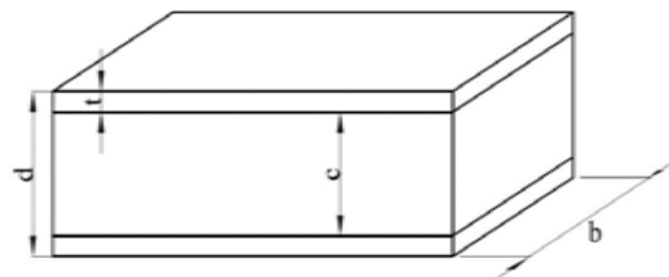

Figure 11- Equivalent Composite Structure Geometry

The value of critical load has been adopted from the Experimental Analysis which is calculated for this test is 1930.8 N. Using the ASTM C393-00 standard formulae, the following properties of sandwich panel can be obtained-

a. Flexural Rigidity or Bending Stiffness,

$$
\mathrm{D}=\mathrm{E}\left(\mathrm{d}^{3}-\mathrm{c}^{3}\right) \mathrm{b} / 12
$$

b. Shear Rigidity,

$$
\mathrm{U}=\mathrm{G}(\mathrm{d}+\mathrm{c})^{2 * b} / 4 \mathrm{c}
$$

c. Panel Deflection,

$$
\text { Def. }=\underline{\mathrm{PL}^{\underline{3}}}+\underline{\mathrm{PL}}
$$

Where,

Sandwich Width (b), Span length (L), Critical force (P), Young's modulus (E) of face sheet (61340 MPA) and Shear modulus (G) of core (98-102 MPA) are the different notations used.

Using the equations 1,2,3 and different corresponding values for chosen sandwich structure, the values obtained for D, U and Deformation are 201.46 $\mathrm{MNmm}^{2}$, 64576.77 $\mathrm{N}$ and $1.8 \mathrm{~mm}$ respectively.

Using Ultimate load as $1930.8 \mathrm{~N}$ and Deflection as $1.8 \mathrm{~mm}$, the value of stiffness obtained is $1072.66 \mathrm{~N} / \mathrm{mm}$.

\section{Results and discussion}

The results obtained from 3 types of analyses have been compared to check the degree of agreement between them as shown in Table 5 .

Table 5- Results obtained from 3 types of analyses

\begin{tabular}{|c|c|c|c|}
\hline Analysis & $\begin{array}{c}\text { Load } \\
\mathbf{( N )}\end{array}$ & $\begin{array}{c}\text { Deflection } \\
(\mathbf{m m})\end{array}$ & $\begin{array}{c}\text { Stiffness } \\
\mathbf{( N / m m )}\end{array}$ \\
\hline FE & 1949.5 & 2.017 & 966.53 \\
\hline Experimental & 1930.8 & 1.82 & 1060.88 \\
\hline Analytical & 1930.8 & 1.8 & 1072.66 \\
\hline
\end{tabular}

It is evident from the Table 5 that the value of the stiffness of the sandwich panels obtained through Experimental and Analytical Analysis is very close to the value of stiffness obtained through the Numerical Analysis.

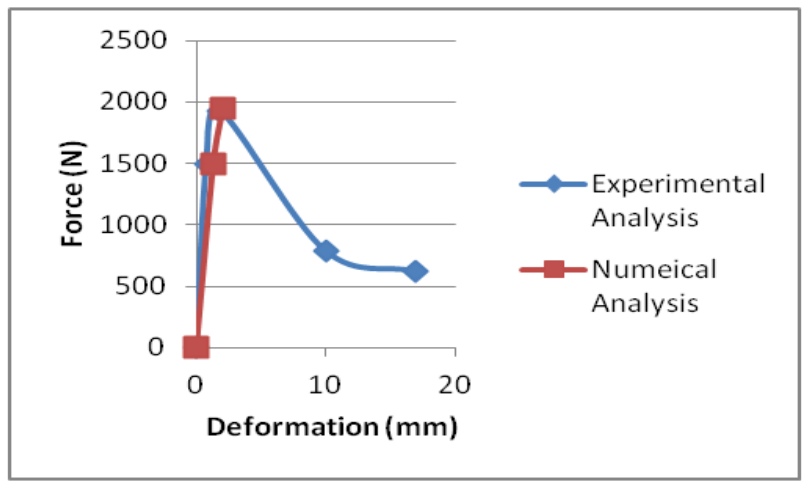

Figure 12- 3РBT Curve for Load vs. Deflection for Experimental and Numerical Analysis

The Figure 12 shows 3PBT Curve for Load vs. Deflection for Experimental and Numerical Analysis. The experimental analysis curve can be broken into two parts by peak load. The Initial part from origin to highest peak is called Pre-buckling stage showing a linear elastic deformation of the sandwich panel. The Peak load obtained through Experimental Analysis is $1930.8 \mathrm{~N}$ at a Deflection of $1.82 \mathrm{~mm}$. The slope of the straight line for this part is the stiffness of the sandwich panel which is $1060.88 \mathrm{~N} / \mathrm{mm}$. In the later stage after peak load, the force drops rapidly and a wide platform zone has been observed and the panel and core materials sink on the whole and the panel strength decreases rapidly.

From Table 5 and Figure 11 it is evident that the different types of Analysis are in good agreement with each other.

\section{Conclusion}

In this study, Modelling of a composite sandwich structure, having Carbon Fibre Reinforced Plastic (CFRP) face sheets and a regular hexagon Kevlar ${ }^{\circledR}$ Honeycomb core material, in the form of an equivalent solid, has been done. 'Gibson and Ashbey model' has been employed to determine the equivalent orthotropic 
properties of Kevlar® Honeycomb core. 3РBT has been performed on sandwich panel using Ansys as per C393 ASTM standard and ultimate load and deformation has been calculated.

To find the stiffness from Experimental analysis, a composite sandwich has been fabricated and a 3PBT also has been performed on it. Also the value of stiffness has been found analytically using the ASTM C 399-00.

The stiffness value obtained from Numerical Analysis is successfully compared with the experimental and Analytical solution. So the numerical model predict to an excellent stage of the static behaviour of the material whilst compared with the experiments.

The elastic orthotropic properties of Kevlar® honeycomb core have been successfully determined using Gibson and Ashbey model.

This model and modelling procedure can be used for determining the flexural properties of similar type of sandwich panels.

\section{Acknowledgements}

I am highly thankful to Mechanical Engineering Department of G. B. Pant Government Engineering College, New Delhi, India for allowing me to use the labs for the experimental work for this research work.

\section{Nomenclature}

$\begin{array}{ll}\text { CRFP } & \text { Carbon fiber Reinforcement fiber } \\ \text { GFRP } & \text { Glass fiber Reinforcement fiber } \\ \text { 3PBT } & \text { Three Point Bend Test } \\ \text { FEA } & \text { Finite Element Analysis } \\ \text { PK2 } & \text { Kevlar Type } \\ \text { ASTM } & \text { American Society for Testing and Materials } \\ \text { UTM } & \text { Universal Testing Machine } \\ \text { MPa } & \text { Mega Pascal } \\ \rho^{*}{ }_{\mathrm{c}} & \text { Density of Core } \\ \rho^{*}{ }_{\mathrm{s}} & \text { Density of Solid material for core making } \\ \mathrm{G}_{\mathrm{s}} & \text { Shear Modulus of Solid Material } \\ \mathrm{E}_{\mathrm{s}} & \text { Young’s Modulus of Solid Material } \\ \mathrm{E}^{*}{ }_{\mathrm{x}, \mathrm{y}, \mathrm{z}} & \text { In and Out plane Young's Modulus of Core } \\ \mathrm{V}^{*}{ }_{\mathrm{xy}} & \text { In Plane Poission's Ratio of Core } \\ \mathrm{V}^{*}{ }_{\mathrm{xz}, \mathrm{yz}} & \text { Out Plane Poission's Ratio of Core } \\ \mathrm{G}^{*}{ }_{\mathrm{xy}} & \text { In Plane Shear Modulus of Core } \\ \mathrm{G}^{*}{ }_{\mathrm{xz}, \mathrm{yz}} & \text { Out Plane Shear Modulii of Core }\end{array}$

\section{References}

1) S. Kalpak, S. Nagesh and D. Manoj, “A Comparative Study of Hot Rolled Section (HRS) and Cold Formed Section under Combined Bending and Shear using ANSYS.16”, International Journal for Scientific Research \& Development, 5(2)1399-1403 (2017).

2) J. Arbaoui, Y. Schmitt and F. Royer, "Effect of core thickness and intermediate layers on mechanical properties of polypropylene honeycomb multi-layer sandwich structures", Archives of metallurgy and material,59(1)11-16(2014).doi:10.2478/amm-20140002.

3) M.A. Khan, A.K. Syed, H. Ijaz and R.M.B.R. Shah, "Experimental and numerical analysis of flexural and impact behaviour of glass/pp sandwich panel for automotive structural applications”, Advanced Composite Materials, (2017). doi:10.1080/09243046.2017.1396199.

4) H. Ijaz, M. Asad, A. Memon, K. B. Ahmed, H. Abbasi and A. N. Laghari, "Strain Energy Based Homogenization Method to Find The Equivalent Orthotropic Properties of Sandwich Structures", Sindh Univ. Res. Jour. (Sci. Ser.), 46(1) 93-98 (2014)

5) C. W. Schwingshack, G. S. Aglietti and P. R. Cunningham, "Determination of Honeycomb Material Properties: Existing Theories and an Alternative Dynamic Approach”, Journal of Aerospace Engineering, 19(3) 177-183 (2006). doi:10.1061/(asce)0893-1321(2006)19:3(177).

6) C. Chamis, R. Aiello and P. Murthy, "Fibre composite sandwich thermostructural behavior: Computational simulation”, Journal of Composite Technolgy and Research, 10,93-99 (1988).

7) H. Ijaz, W. Saleem, M. Zain-ul-Abdein and T. Mabrouki, "Finite Element Analysis of Bend Test of Sandwich Structures Using Strain Energy Based Homogenization Method", Hindawi Advances in Materials Science and Engineering. (2017), Article ID 8670207:1-10. doi.org/10.1155/2017/8670207.

8) L. Czechowski, J. Jankowski and M. Kotełko, "Experimental and numerical three-point bending test for sandwich beams", Journal of KONES Power train and Transport, 24(3) 53-62 (2017), doi: 10.5604/01.3001.0010.3071.

9) M. Hussain, R. Khan, N. Abbas, "Experimental and computational studies on honeycomb sandwich structures under static and fatigue bending load”, Journal of King Saudi University, 31:222-229 (2019). doi.org/10.1016/j.jksus.2018.05.012.

10) S. Goswami, "On the Prediction of Effective Material Properties of Cellular Hexagonal Honeycomb Core”, Journal Of Reinforced Plastics And Composites, 25(4) 393-405 (2006). doi: $0.1177 / 0731684405060567$.

11) L.. Gornet, S. Marguet, G. Marckmann, "Finite Element modeling of Nomex ${ }^{\circledR}$ honeycomb cores: Failure and effective elastic properties", International Journal Computer Material \& Continua Tech Science, 2006, 4. ffhal-01006894f.

12) O. Çinar, M. Erdal and A. Kayran, “Accurate Equivalent Models of Sandwich Laminates with Honeycomb Core and Composite Face Sheets via Optimization Involving Modal Behavior”, Journal of Sandwich Structures \& Materials, 19(2), 139-166 
(2017), doi:10.1177/1099636215613934

13) J. M. Lister. (2014). "Study the effects of core orientation and different face thicknesses on mechanical behavior of honeycomb sandwich structures under three point bending”.

14) L.L. Liu, H. Wang and Z.W. Guan, "Numerical models with layered elements for Nomex honeycomb core under flat wise compression”, $20^{\text {th }}$ International Conference on Composite Materials, Copenhagen, 19-24th July 2015.

15) D. M. Abouelella, S. K. Fateen and M. K. Fouad, "Multiscale Modeling Study of the Adsorption of $\mathrm{CO}_{2}$ Using Different Capture Materials", EVERGREEN Joint Journal of Novel Carbon Resource Sciences \& Green Asia Strategy, 05(1), 43-51 (2018).

16) H. Herranen, O. Pabut, M. Eerme and J. Majak, "Design and Testing of Sandwich Structures with Different Core Materials”, Materials Science, 18(1) 45-50 (2012).

17) A. Mahyudin, S. Arief, H. Abral, Emriadi, M. Muldarisnur and M. P. Artika, "Mechanical Properties and Biodegradability of Areca Nut Fiber-reinforced Polymer Blend Composites”, EVERGREEN Joint Journal of Novel Carbon Resource Sciences \& Green Asia Strategy, 7(3) 366-372 (2020).

18) D. G. Vamja and G. G. Tejani, "Experimental Test on Sandwich Panel Composite Material”, International Journal of Innovative Research in Science, Engineering and Technology, 2(7) 3047-3054 (2013).

19) A. Kumar, A. K. Chanda and S. Angra, "Optimization of Stiffness Properties of Composite Sandwich using Hybrid Taguchi-GRA-PCA”, EVERGREEN Joint Journal of Novel Carbon Resource Sciences \& Green Asia Strategy, 08(2) 301-317 (2021).

20) S. P. Dwivedi, M. Maurya, N. K. Maurya, A. K. Srivastava, S. Sharma and A. Saxena, “Activated Carbon from Bagasse and its Application for Water Vapor Adsorption”, EVERGREEN Joint Journal of Novel Carbon Resource Sciences \& Green Asia Strategy, 07(3), 409-416 ( 2020).

21) A. Gupta, L. Nagdeve and P. K. Arora, "EDM Parametric Study of Composite Materials: A Review”, EVERGREEN Joint Journal of Novel Carbon Resource Sciences \& Green Asia Strategy, 07(4), 519-529 (2020).

22) S.S. Chauhan and S.C. Bhaduri, "Structural analysis of a Four-bar linkage mechanism of Prosthetic knee joint using Finite Element Method”, EVERGREEN Joint Journal of Novel Carbon Resource Sciences \& Green Asia Strategy, 7(2), 209-215 (2020).

23) ASTM C393 / C393M-20, Standard Test Method for Core Shear Properties of Sandwich Constructions by Beam Flexure, ASTM International, West
Conshohocken, PA, 2020, www.astm.org.

24) Gibson, L., \& Ashby, M. “Cellular Solids: Structure and Properties (Cambridge Solid State Science Series). Cambridge: Cambridge University Press. (1997). doi:10.1017/CBO9781139878326.

25) https://www.plascore.com/download/datasheets/hon ycomb_data_sheets/PLA_PK2_2019.pdf.[accessed 2019 Jan. 20]

26) A. Kumar, A. K. Chanda and S. Angra, “Analysis of the effects of varying core thicknesses of Kevlar Honeycomb sandwich structures under different regimes of testing”, Materials Today: Proceedings, 21(2020),1615-1623.doi.org/10.1016/j.matpr.2019.1 1.242 . 